\title{
Cardiac Perforation
}

National Cancer Institute

\section{Source}

National Cancer Institute. Cardiac Perforation. NCI Thesaurus. Code C73502.

The presence of an acquired hole in the heart. Cardiac perforation may or may not be symptomatic and may or may not be self sealing. (ACC) 